\title{
Efficient synthesis of SiOC glasses from ethane, ethylene, and acetylene-bridged polysilsesquioxanes
}

\section{Kazuki Yamamoto $^{a}$, Joji Ohshita ${ }^{b, *}$, Tomonobu Mizumo ${ }^{c}$, Toshinori Tsuru ${ }^{d}$}

\author{
a b c Department of Applied Chemistry, Graduate School of Engineering, Hiroshima University, \\ Higashi-Hiroshima 739-8527, Japan \\ d Department of Chemical Engineering, Graduate School of Engineering, Hiroshima University, \\ Higashi-Hiroshima 739-8527, Japan
}

Corresponding author. E-mail address: jo@ hiroshima-u.ac.jp (J. Ohshita)

\section{Introduction}

Polymer derived ceramics (PDCs) have attracted much attention [1-3], because of their processability. Ceramic fibers, films, and coatings are readily obtained by melting or solution process of the precursor polymers, followed by pyrolysis in an inert atmosphere. Various organosilicon polymers have been reported as the precursors of silicon-based ceramics. Typical examples include polycarbosilane $\left[\mathrm{Si}(\mathrm{H})\left(\mathrm{CH}_{3}\right) \mathrm{CH}_{2}\right]_{n}$ and polysilazane $\left(\mathrm{SiH}_{2} \mathrm{NH}\right)_{n}$ as silicon carbide (SiC) [4-7] and silicon nitride $\left(\mathrm{Si}_{3} \mathrm{~N}_{4}\right)$ precursors [8, 9], respectively. To increase the yields of PDCs, unsaturated carbon units are often introduced into the precursor polymers [7]. The unsaturated units undergo cross-linking reactions during the pyrolysis process, thus avoiding the liberation of volatiles and this process usually provides carbon-rich ceramics. Silicon oxycarbide ( $\mathrm{SiOC}$ ) glasses whose composition is described as $\mathrm{SiO}_{x} \mathrm{C}_{y}$ are known as blackish amorphous solids, which shows high thermal stability even over $1500{ }^{\circ} \mathrm{C}$ in air and intermediate properties between silica and SiC. The glasses are usually prepared by sol-gel reactions of trialkoxyalkylsilanes or trichloroalkylsilanes, followed by pyrolysis of the resulting polysilsesquioxane gels around $1000{ }^{\circ} \mathrm{C}$ in an inert atmosphere, while $\mathrm{SiC}$ and $\mathrm{SiO}_{2}$ crystalline gradually form in the substances when heated 
over $1000^{\circ} \mathrm{C}$. Recently, various types of $\mathrm{SiOC}$ ceramics have been applied as optical and electrical materials [10-14].

Porous silica materials have been well studied. Of those, organically bridged polysilsesquioxanes, which are synthesized via the sol-gel process of organic group-bridged trialkoxysilanes $\left[\left(\mathrm{R}^{\prime} \mathrm{O}\right)_{3} \mathrm{SiRSi}\left(\mathrm{OR}^{\prime}\right)_{3}\right]$ have attracted recent attention. In these materials, the organic unit (R) bridging two Si atoms expands silica network as a spacer, leading to the use for various functional materials, such as catalysts, low density materials, and separation membranes [15-20]. The bridged polysilsesquioxanes have been also investigated as precursors of SiOC glasses [21, 22]. For example, Aravind et al reported that pyrolysis of ethane-bridged silica prepared by the sol-gel reaction of bis(triethoxysilyl)ethane in an inert atmosphere provided an SiOC glass with a large surface area [21]. However, much less is known for the SiOC formation from other bridged silica.

Previously, we have investigated polymerization behavior and gel properties of ethane, ethylene and acetylene-bridged triethoxysilanes [23]. It has been also demonstrated that the resulting bridged silica may be applied to gas and water separation membranes and the introduction of rigid ethylene and acetylene bridges enhances the permeability of the membranes likely because of the enlargement of the nanopore structures $[24,25]$. It seems therefore interesting to us to investigate how the bridge structures affect the structure of SiOC derived from these bridged silica. In addition, the introduction of unsaturated hydrocarbon bridges is anticipated to increase ceramic yield. This is an important factor that minimizes curing shrinkage in pyrolysis of films, coatings, and fibers to reduce the risk of cracks and deformation [26-27]. In this paper, we describe the formation of SiOC glasses from these bridged silica and their structures.

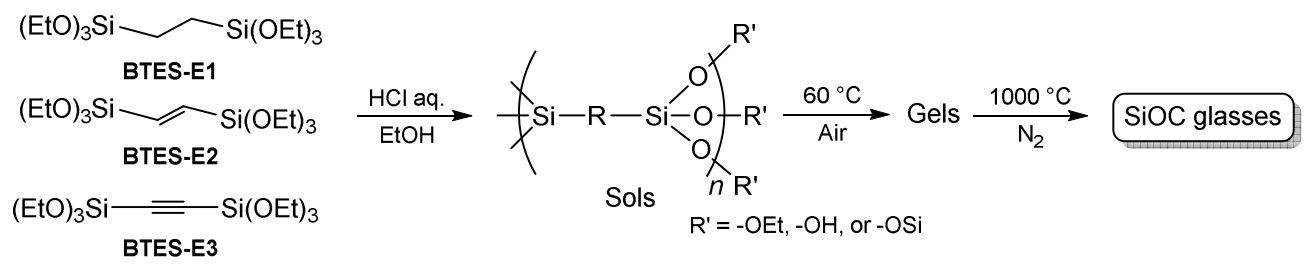

Scheme 1. Preparation of silicon oxycarbide glasses from bridged trialkoxysilanes.

\section{Experimental}




\subsection{General}

Bis(triethoxysilyl)ethane and bis(triethoxysilyl)ethylene were obtained from Gelest Inc. These materials were used as received without purification. Bis(triethoxysilyl)acetylene was prepared as reported previously [16]. Solid state magic angle spinning (MAS) ${ }^{13} \mathrm{C}$ and ${ }^{29} \mathrm{Si}$ NMR spectra were obtained on a Varian 600PS spectrometer using a $6 \mathrm{~mm} \phi$ spinner. IR spectra were obtained on sample powders using a Shimadzu IRAffinity-1 spectrometer equipped with an attenuated total reflection (ATR) attachment. Thermogravimetric analysis (TGA) was carried out on a SII EXSTAR TG-DTA6200 thermal analyzer. The gels were first heated at $100{ }^{\circ} \mathrm{C}$ for $30 \mathrm{~min}$ to remove adsorbed water then measurements were performed at the heating rate of $10{ }^{\circ} \mathrm{C} / \mathrm{min}$ under a nitrogen flow (ca $30 \mathrm{~mL} / \mathrm{min}$ ) or in air. Electron probe micro analysis (EPMA) was carried out on a JEOL JXA-8200 spectrometer for the samples embedded in epoxy resin mounts.

\subsection{Preparation of BTES-E1, BTES-E2, and BTES-E3 gels and SiOC ceramics}

In a $50 \mathrm{~mL}$ vial equipped with a magnetic stirrer, BTES-E1 $(0.5 \mathrm{~g}, 5 \mathrm{mmol})$, ethanol $(2.30 \mathrm{~g}, 50$ mmol), 1 wt. $\% \mathrm{HCl}$ aq. (0.308 $\mathrm{g}, \mathrm{HCl} 0.5 \mathrm{mmol}$ ), and water $0.453 \mathrm{~g}$ (total $\mathrm{H}_{2} \mathrm{O} 300 \mathrm{mmol}$ ) were placed (molar ratio of BTES-E1/HCl/EtOH/ $\mathrm{H}_{2} \mathrm{O}=1 / 0.1 / 10 / 60$ ) and the vial was sealed with a screw cap in air. The mixture was stirred for $3 \mathrm{~h}$ at room temperature and the vial was then heated at $60{ }^{\circ} \mathrm{C}$ for $12 \mathrm{~h}$ to provide Gel-E1 as a colorless powder. Gels Gel-E2 and E3 were obtained from BTES-E2 and BTES-E3, respectively, in a fashion similar to that above.

The resulting gel powders were heated from $25{ }^{\circ} \mathrm{C}$ to $1000{ }^{\circ} \mathrm{C}$ at a rate of $10{ }^{\circ} \mathrm{C} / \mathrm{min}$ then at $1000{ }^{\circ} \mathrm{C}$ for $30 \mathrm{~min}$ under gentle nitrogen gas flow (ca. $100 \mathrm{~mL} / \mathrm{min}$ ) to provide black silicon oxycarbide glasses SiOC-E1, E2, and E3, which were analyzed by IR, solid state MAS NMR, and EPMA.

\section{Results and discussion}

\subsection{Gel preparation and pyrolysis}


The bridged silica gels Gel-E1, E2, and E3 were obtained as colorless powders by acid catalyzed sol-gel polymerization of BTES-E1, E2 and E3, respectively, followed by evaporation of all volatiles at $60{ }^{\circ} \mathrm{C}$ for $12 \mathrm{~h}$. Table 1 shows summery of the gel preparation, including the monomer weights, yields, and reaction ratios. The reaction ratios are calculated as follows (eq 1) and indicate the degree of conversion from Si-OEt to Si-O-Si units.

$$
\text { Reaction ratio }(\%)=\frac{\text { Monomer weight }- \text { gel weight }}{\left(\text { Monomer weight }- \text { theoretical weight of } \mathrm{RSi}_{2} \mathrm{O}_{3}\right)} \times 100
$$

The reaction ratios for Gel-E1, E2, and $\mathbf{E 3}$ are $77-86 \%$, indicating that most of the Si-OEt groups were converted to $\mathrm{Si}-\mathrm{O}-\mathrm{Si}$ bonds, although $\mathrm{Si}-\mathrm{OEt}$ and $\mathrm{Si}-\mathrm{OH}$ groups remained to an extent. It is not unusual that the sol-gel reactions did not complete. Indeed, the reactivity of Si-OEt bonds is known to be suppressed as the ethoxy groups of $\mathrm{Si}(\mathrm{OEt})_{3}$ are hydrolyzed [28].

Table 1. Synthesis of bridged silica gels

\begin{tabular}{cccc} 
Alkoxysilanes & Monomer weight /g & Yield /g & Reaction ratio $/ \%$ \\
\hline BTES-E1 & 0.500 & 0.246 & 81 \\
BTES-E2 & 0.500 & 0.258 & 77 \\
BTES-E3 & 0.500 & 0.226 & 86 \\
\hline
\end{tabular}

Fig. 1 shows photographs of the presently prepared gels and glasses. Gels Gel-E1 and E3 are colorless, while Gel-E2 is pale yellow, likely due to some oxidation of $-\mathrm{CH}=\mathrm{CH}$ - groups. On the other hand, the SiOC glasses are black solids, nearly keeping the bulk shapes of the starting gels. 


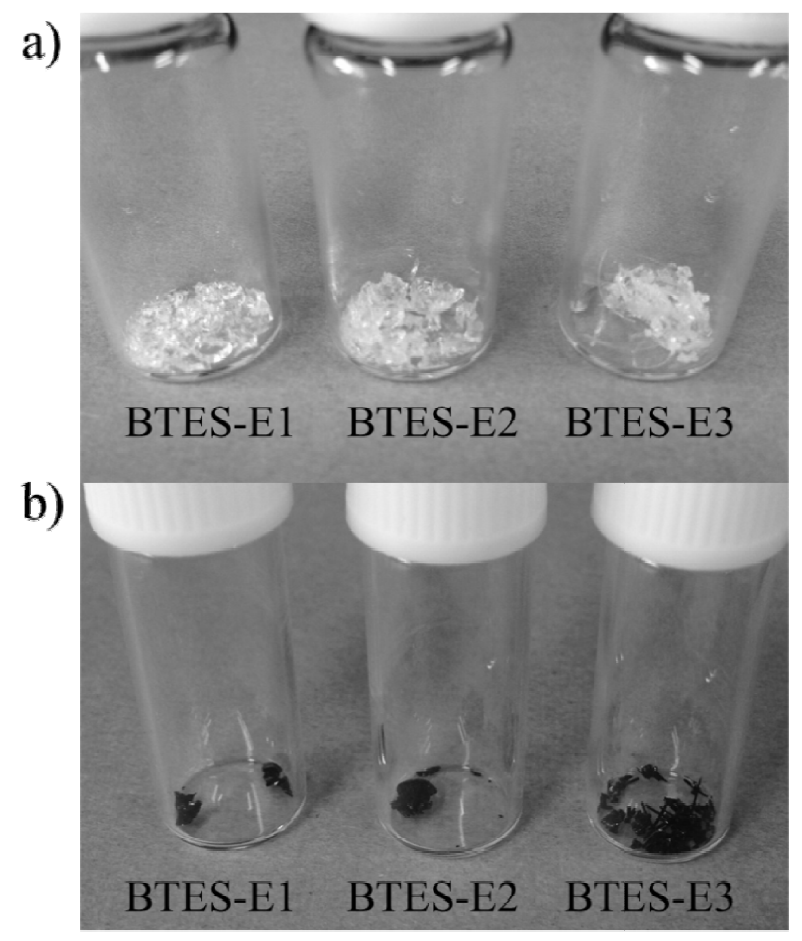

Fig. 1. Photographs of Gel-E1, E2, and E3 (a, from left to right) and SiOC-E1, E2, and E3 (b, from left to right), derived from BTES-E1, -E2, and -E3, respectively.

To evaluate the thermal behaviors, we carried out TGA of the gels as shown in Fig. 2. The gels were first heated at $100{ }^{\circ} \mathrm{C}$ for $30 \mathrm{~min}$ to remove adsorbed water then measurements were performed at the heating rate of $10{ }^{\circ} \mathrm{C} / \mathrm{min}$. The first weight loss around $200-400{ }^{\circ} \mathrm{C}$ (a) is assigned to further condensation of remaining $\mathrm{Si}-\mathrm{OH}$ groups leading to $\mathrm{Si}-\mathrm{O}-\mathrm{Si}$ linkages [29, 30], while the second weight loss around $500-700{ }^{\circ} \mathrm{C}(\mathrm{b})$ is likely due to decomposition of the organic groups. Finally, nearly flat TG curves are obtained from all the samples (c) around $700{ }^{\circ} \mathrm{C}-1000{ }^{\circ} \mathrm{C}$. At $1000{ }^{\circ} \mathrm{C}$, the ceramic yields of SiOC-E1, E2, and E3 were 87.2\%, $90.4 \%$, and $95.2 \%$, respectively. Presumably, cross-linking reactions with respect to the unsaturated bridging units during the heating process are responsible for the increased ceramics yields. 


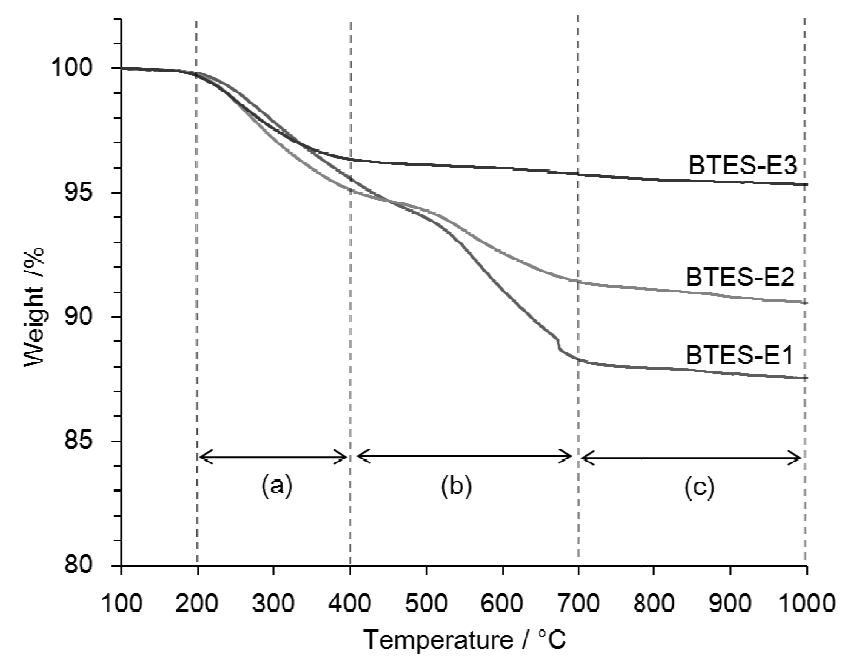

Fig. 2. TGA curve of the gels under nitrogen flow from $100{ }^{\circ} \mathrm{C}$ to $1000{ }^{\circ} \mathrm{C}$.

\subsection{Characterization of SiOC glasses}

The formation of SiOC-E1, E2, and E3 from the corresponding gels was monitored by FT-IR spectroscopy. As shown in the Fig. 3 (a), the spectra of Gel-E1 and E2 reveal bands around 2890 $\mathrm{cm}^{-1}, 1260 \mathrm{~cm}^{-1}, 1050 \mathrm{~cm}^{-1}, 910 \mathrm{~cm}^{-1}$, and $700 \mathrm{~cm}^{-1}$ that are ascribed to $\mathrm{C}-\mathrm{H}$ stretching, $\mathrm{C}-\mathrm{H}$ vending, Si-O-Si vending, Si-OH stretching, and Si-C stretching, respectively. After the gels were heated at $1000{ }^{\circ} \mathrm{C}$ for $30 \mathrm{~min}$, the $\mathrm{C}-\mathrm{H}$ and $\mathrm{Si}-\mathrm{OH}$ stretching bands nearly disappeared and the $\mathrm{Si}-\mathrm{O}-\mathrm{Si}$ and $\mathrm{Si}-\mathrm{C}$ bands were relatively intensified, indicating the formation of Si-O-C glasses. As shown in Fig. 3 (b), Gel-E3 showed similar thermal behavior, while a signal at $2060 \mathrm{~cm}^{-1}$ ascribed to $-\mathrm{C} \equiv \mathrm{C}$ stretching decreased upon heated at $300{ }^{\circ} \mathrm{C}$ and disappeared at $500{ }^{\circ} \mathrm{C}$. Since TGA showed no weight loss between $300{ }^{\circ} \mathrm{C}$ and $500{ }^{\circ} \mathrm{C}$, as shown in Fig. 2, the decease and disappearance of $-\mathrm{C} \equiv \mathrm{C}$ band in the IR spectra is not due to the liberation of acetylene-containing organic units, but to cross-linking reactions of the acetylene units, such as trimerization forming benzene rings. 

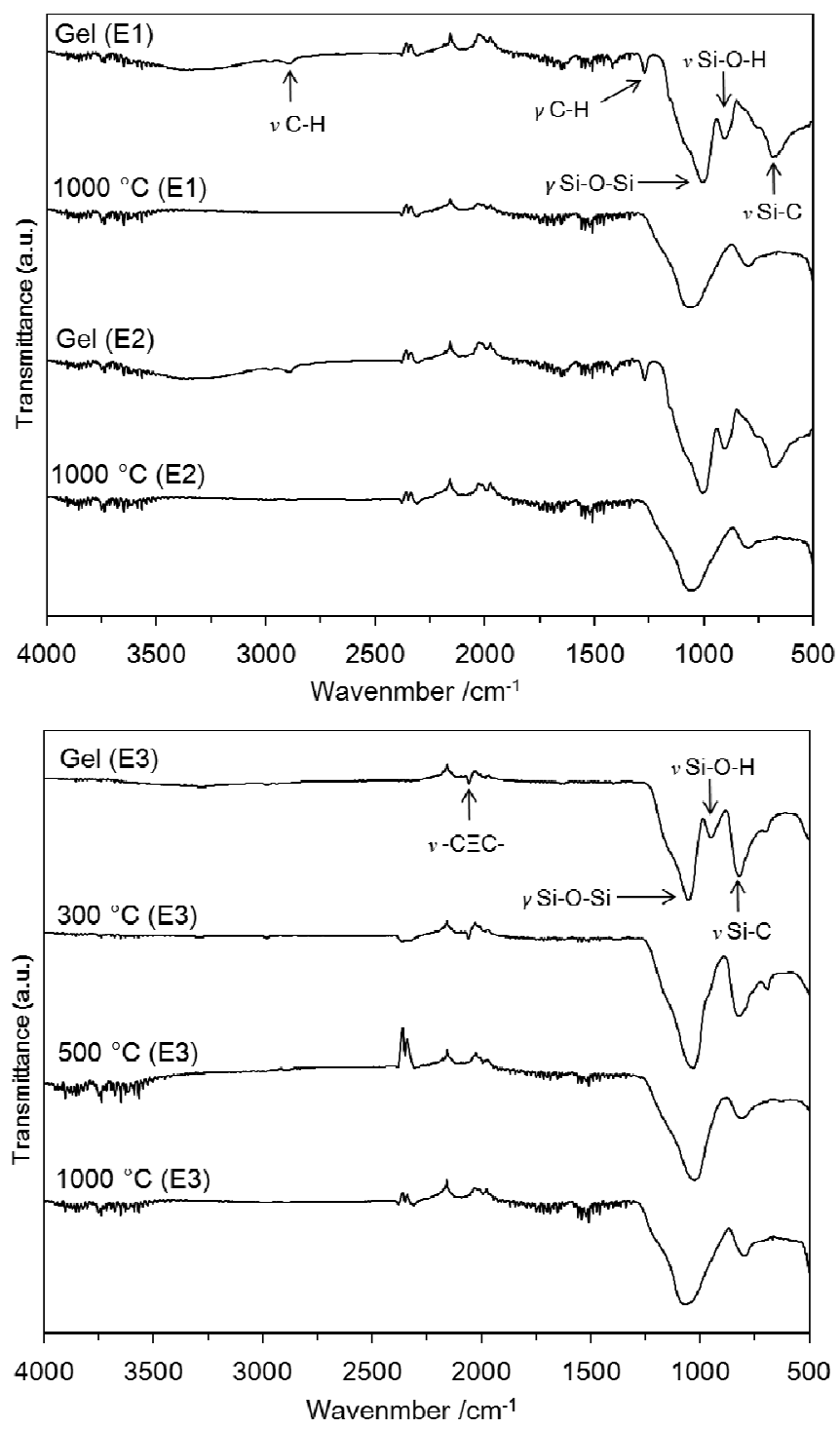

Fig. 3. FT-IR spectra of GE1, GE2 (a), and GE3 (b) before and after heating.

Solid state MAS ${ }^{13} \mathrm{C}$ and ${ }^{29} \mathrm{Si}$ NMR spectra of gels Gel-E1, E2, and E3 and glasses SiOC-E1, E2, and $\mathbf{E 3}$ are shown in Fig. 4 and 5, respectively. The ${ }^{13} \mathrm{C}$ NMR spectra of the gels reveal bridging carbon and -OEt signals. After heating the gels at $1000{ }^{\circ} \mathrm{C}$, no clear peaks were observed, indicating the formation of SiOC glasses containing a variety of carbons. In the ${ }^{29} \mathrm{Si} \mathrm{NMR}$ spectra, Gel-E2 and $\mathbf{E 3}$ show $\mathrm{T}^{n}\left[\mathrm{RSi}(\mathrm{OSi})_{n}\left(\mathrm{OR}^{\prime}\right)_{3-n}\right]\left(n=1-3, \mathrm{R}^{\prime}=\mathrm{H}\right.$ or Et $)$ signals, while for Gel-E1 the signals were observed as a single peak probably due to overlapping. After pyrolysis of the gels, two peaks were observed ascribed to $\mathrm{T}^{n}\left[\mathrm{RSi}(\mathrm{OSi})_{n}(\mathrm{OH})_{3-n}\right]$ and $\mathrm{Q}^{n}\left[\mathrm{Si}(\mathrm{OSi})_{n}(\mathrm{OH})_{4-n}\right]$, suggesting 
that thermal decomposition of the organic bridges partly occurred leading to the formation of Q structures.
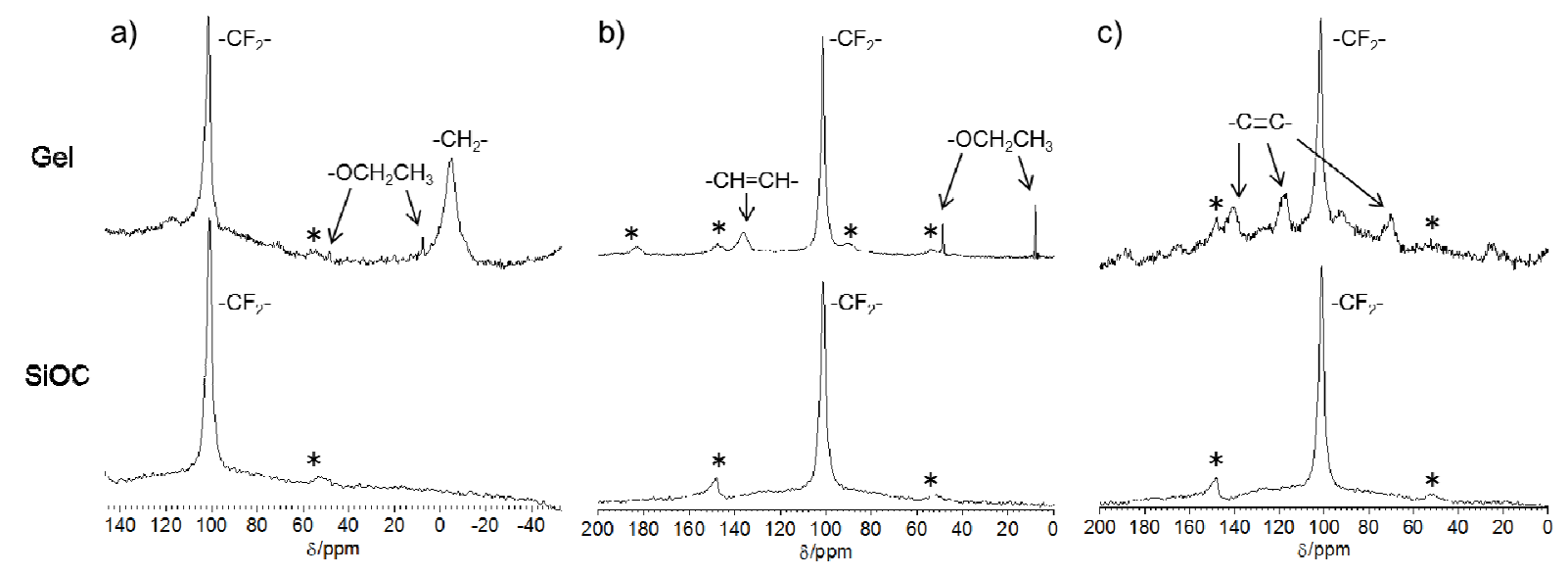

Fig. 4. Solid state MAS ${ }^{13} \mathrm{C}$ spectra of GE1 and SE1 (a), GE2 and SE2 (b), and GE3 and SE3 (c). Peaks ascribed to fluoroalkyls of spinner caps and spinning side band are observed.

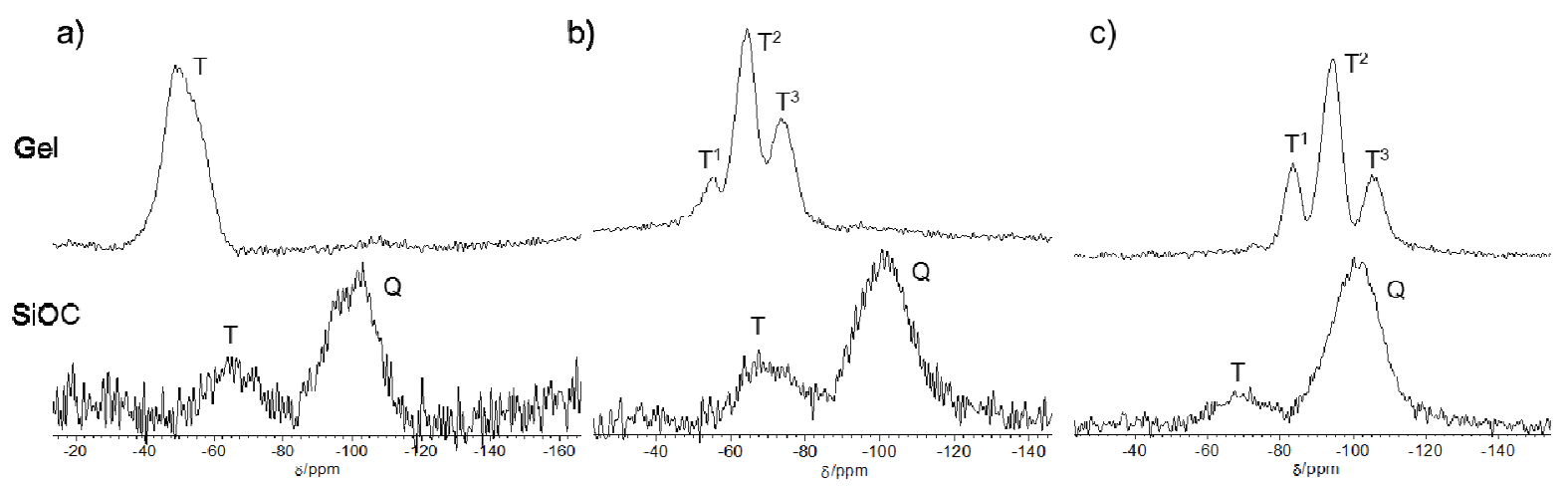

Fig. 5. Solid state MAS ${ }^{29}$ Si NMR spectra of Gel- and SiOC-E1 (a), Gel- and SiOC-E2 (b), and Gel- and SiOC-E3 (c).

\section{3 Composition of SiOC glasses}

Composition of SiOC glasses was determined by means of two methods, ${ }^{29} \mathrm{Si}$ MAS NMR 
spectrometry and EPMA. ${ }^{29} \mathrm{Si}$ NMR spectra can provide information concerning the Si bonding to $\mathrm{C}$ or $\mathrm{O}$, that is, $\mathrm{T}\left[\mathrm{SiCO}_{3}\right]$ and $\mathrm{Q}\left[\mathrm{SiO}_{4}\right]$ signals appear separately, as presented in Fig. 5. No signals of $\mathrm{D}\left[\mathrm{SiC}_{2} \mathrm{O}_{2}\right]$ or $\mathrm{M}\left[\mathrm{SiC}_{3} \mathrm{O}\right]$ structures were observed. Thus, $\mathrm{O} / \mathrm{Si}$ and $\mathrm{C} / \mathrm{Si}$ atom ratios were calculated on the basis of eq 2 and 3, following the previous literature [31], where $F\left(\mathrm{SiO}_{x} C_{4-x}\right)$ is the unit ratio of the structure determined by the ${ }^{29} \mathrm{Si} \mathrm{NMR} \mathrm{spectra}$ and $x$ is the number of oxygen atoms attached to the silicon atom. The data are summarized in Table 2. Glass material SiOC-E3 shows the lowest $\mathrm{SiCO}_{3}$ content of 0.14, while those of BTES-E2 and BTES-E3 are 0.21 and 0.23, respectively.

$$
\begin{aligned}
& \frac{\mathrm{O}}{\mathrm{Si}}=\frac{\sum_{x=0}^{4} F\left(\operatorname{SiO}_{x} C_{4-x}\right) x}{2} \\
& \frac{\mathrm{C}}{\mathrm{Si}}=\frac{\sum_{x=0}^{4} F\left(\operatorname{SiO}_{x} C_{4-x}\right)(4-x)}{4}
\end{aligned}
$$

On the other hand, EPMA is a quantitative method to estimate the element compositions. Table 3 shows compositions of the $\mathrm{SiOC}$ glasses based on the EPMA results, by assuming silicon and oxygen atoms are involved only as T or Q units. As presented in Table 2, SiOC-E3 shows the lowest $\mathrm{T}$ content among the glasses, but shows the highest free carbon content, similarly to the results of ${ }^{29} \mathrm{Si}$ NMR analysis.

Table 2. Composition of SiOC glasses based on ${ }^{29} \mathrm{Si}$ NMR analysis

\begin{tabular}{cccc}
\multirow{2}{*}{$\begin{array}{c}\text { SiOC } \\
\text { glasses }\end{array}$} & Composition & \multicolumn{2}{c}{ Structure (\%) } \\
\cline { 3 - 4 } (with free carbon) & $\mathrm{SiCO}_{3}$ & $\mathrm{SiO}_{4}$ \\
\hline SiOC-E1 & $\mathrm{Si} \mathrm{C}_{0.21} \mathrm{O}_{1.86}+\mathrm{xC}_{\text {free }}$ & 28.6 & 71.4 \\
SiOC-E2 & $\mathrm{Si} \mathrm{C}_{0.23} \mathrm{O}_{1.84}+\mathrm{xC}_{\text {free }}$ & 31.3 & 68.7 \\
SiOC-E3 & $\mathrm{Si} \mathrm{C}_{0.14} \mathrm{O}_{1.91}+\mathrm{xC}_{\text {free }}$ & 18.9 & 81.1 \\
\hline
\end{tabular}


Table 3. Composition of SiOC glasses based on EPMA

\begin{tabular}{|c|c|c|c|c|c|}
\hline \multirow{2}{*}{$\begin{array}{l}\mathrm{SiOC} \\
\text { glasses } \\
\end{array}$} & \multirow{2}{*}{$\begin{array}{c}\text { Composition } \\
\text { (with free carbon) }\end{array}$} & \multirow{2}{*}{$\begin{array}{c}\text { Composition } \\
\text { (total) } \\
\end{array}$} & \multicolumn{3}{|c|}{ Atom $(\%)$} \\
\hline & & & $\mathrm{Si}$ & $\mathrm{C}$ & $\mathrm{O}$ \\
\hline SiOC-E1 & $\begin{array}{c}\text { Si } \mathrm{C}_{0.20} \mathrm{O}_{1.60}+ \\
0.50 \mathrm{C}_{\text {free }}\end{array}$ & Si $\mathrm{C}_{0.70} \mathrm{O}_{1.60}$ & 30.3 & 21.3 & 48.4 \\
\hline SiOC-E2 & $\begin{array}{c}\mathrm{Si} \mathrm{C}_{0.16} \mathrm{O}_{1.68}+ \\
0.65 \mathrm{C}_{\text {free }}\end{array}$ & $\mathrm{Si} \mathrm{C}_{0.81} \mathrm{O}_{1.68}$ & 28.7 & 23.1 & 48.1 \\
\hline SiOC-E3 & $\begin{array}{c}\text { Si } \mathrm{C}_{0.10} \mathrm{O}_{1.81}+ \\
0.76 \mathrm{C}_{\text {free }} \\
\end{array}$ & $\mathrm{Si} \mathrm{C}_{0.85} \mathrm{O}_{1.81}$ & 26.9 & 22.8 & 48.6 \\
\hline
\end{tabular}

\section{Conclusions}

SiOC glasses SiOC-E1, E2, and $\mathbf{E 3}$ were obtained as blackish solid by the hydrolysis/condensation polymerization of bridged triethoxysilanes BTES-E1, E2, and E3, followed by pyrolysis in nitrogen at $1000{ }^{\circ} \mathrm{C}$. They gave SiOC glasses in excellent yields. BTESE-E3 exhibited the highest glass yield of $95.2 \%$, while those of SiOC-E1 and E2 were $87.2 \%$ and $90.4 \%$, respectively, indicating that the introduction of unsaturation increased the ceramic yields. Element compositions and ratios of $\mathrm{T}$ and $\mathrm{Q}$ structures of SiOC-E1, E2 and $\mathbf{E 3}$ were determined to be by EPMA and ${ }^{29} \mathrm{Si}$ MAS NMR spectrometry, respectively, and it was noted that the bridge structures affected the composition and the higher unsaturation led to the higher content of free carbon. Controlling the structures of SiOC glasses that closely relate their functionalities would be interesting and noteworthy.

\section{Acknowledgment}

This research was supported by Core Research for Evolutionary Science and Technology (CREST), Japan Science and Technology Agency (JST). The EPMA measurements were 
performed at the Natural Science Center for Basic Research and Development (N-BARD), Hiroshima University.

\section{References}

[1] R. Riedel, G. Mera, R. Hauser, A. Klonczynski, J. Ceram. Soc. Jpn. 114 (2006) 425-444.

[2] P. Colombo, G. Mera, R. Riedel, G. D.Soraru, J. Am. Ceram. Soc. 93 (2010) 1805-1837.

[3] B. V. M. Kumar, Y. W. Kim, Sci. Technol. Adv. Mater. 11 (2010) 044303 (16pp).

[4] H. Q. Ly, R. Taylor, R. J. Day, F. Heatley, J. Mater. Sci. 36 (2001) 4037-4043.

[5] T. Nagano, K. Sato, T. Saitoh, Y. Iwamoto, J. Ceram. Soc. Jpn. 114 (2006) 533-538.

[6] S. Castelletto, B. C. Johnson, V. Ivády, N. Stavrias, T. Umeda, A. Gali, T. Ohshima, Nature Mater. 13 (2014) 151-156

[7] R. J. P. Corriu, Ph. Gerbier, C. Guerin, B. J. Henner, J. Organometallic Chem. 449 (1993) $111-118$.

[8] M. Hörz, A. Zern, F. Berger, J. Haug, K. Müller, F. Aldinger, M. Weinmann, J. Eur. Ceram. Soc. 25 (2005) 99-110.

[9] N. Brodie, J. P. Majoral, J. P. Dissont, Inorg. Chem. 32 (1993) 4646-4649.

[10] E. Jeon, H. Kim, J. Yun, J. Ceram. Processing Res. 13 (2012) 239-242.

[11] V. Belot, R. J. P. Corriu, D. Leclercq, P. H. Mutin, A. Vioux, J. Non-Cryst. Solids 176 (1994) $33-44$.

[12] S. Dirè, V. Tagliazucca, L Salvadori, G. D. Sorarù, J. Am. Ceram. Soc. 94 (2011) 3819-3824.

[13] A. Strachota, M. Cerny, Z. Chlup, M. Slouf, J. Hromadkova, J. Plestil, H. Sandova, P. Glogar, Z. Sucharda, M. Havelcova, J. Schweigstillova, I. Dlouhy, V. Kozak, J. Non-Cryst. Solids 358 (2012) 2771-2782.

[14] C. G. Pantano, A. K. Singh H. Zhang, J. Sol-Gel Sci. Technol. 14 (1999) 7-25.

[15] M. P. Kapoor, Q. Yang, S. Inagaki, J. Am. Chem. Soc. 124 (2002) 15176-15177.

[16] M. L. Gomez, D. P. Fasce, R. J.J. Williams, C. M. Previtali, H. A. Montejano, Macromol. Mater. Eng. 295 (2010) 1042-1048. 
[17] B. Rac, P. Hegyes, P. Forgo, A. Molnar, Appl. Catal. A 299 (2006) 193-201.

[18] M. Sasidharan, A. Bhaumik, ACS Appl. Mater. Interfaces 5 (2013) 2618-2625.

[19] M. Kanezashi, S. Miyauchi, H. Nagasawa, T. Yoshioka, T. Tsuru, RSC Adv. 3 (2013)

12080-12083.

[20] M. Burleigh, M. Markowitz, M. Spector, B. Gaber, Environ. Sci. Technol. 36 (2002)

$2515-2518$.

[21] P. R. Aravind, G. D. Soraru, Micropor. Mesopor. Mater. 142 (2011) 511-517.

[22] G. Hasegawa, K. Kanamori, K. Nakanishi,T. Hanada, Chem. Mater. 22 (2010) 2541-2547.

[23] K. Yamamoto, J. Ohshita, T. Mizumo, T. Tsuru, J. Sol-Gel Sci. Technol. 71 (2014) 24-30.

[24] R. Xu, M. Kanezashi, T. Yoshioka, T Okuda, J. Ohshita, T. Tsuru, ACS Appl. Mater. Interfaces 5 (2013) 6147-6154.

[25] R. Xu, I. M. Suhaina, M. Kanezashi, T. Yoshioka, K. Ito, J. Ohshita, T. Tsuru, ACS Appl. Mater. Interfaces 6 (2014) 9357-9364.

[26] S. H. Lee, M. Weinmann, F. Aldinger, Acta Materialia 56 (2008) 1529-1538.

[27] M. Wang, L. Yang, C. Yu, C. C. Xu, Ceram. Intern. 38 (2012) 2449-2454.

[28] D.A. Loy, K. A. Obrey-DeFriend, K. V. Wilson, M. Minke, B. M. Baugher, C. R. Baugher, D. A. Schneider, G. M. Jamison, K. J. Shea, J Non-Cryst. Solids 362 (2013) 82-94.

[29] G. Trimmel, R. Badheka, F. Babonneau, J. LaTournerie, P. Dempsy, D. Bahloul-Houlier, J. Sol-Gel Sci. Technol. 29 (2003) 279-283.

[30] K. Kawahara,Y. Hagiwara, K. Kuroda, Chem. Eur. J. 17 (2011) 13188-13196.

[31] J. Brus, F. Kolar, V. Machovic, J.Svitilova, J. Non-Cryst. Solids 289 (2001) 62-74. 